\title{
Enhanced model of photovoltaic cell/panel/array considering the direct and reverse modes
}

Abdallah Zegaoui, Mohamed Boutoubat, Jean-Paul Sawicki, Fatma Zohra Kessaissia, Abdelkader Djahbar, and Michel Aillerie

Citation: AIP Conference Proceedings 1968, 030015 (2018); doi: 10.1063/1.5039202

View online: https://doi.org/10.1063/1.5039202

View Table of Contents: http://aip.scitation.org/toc/apc/1968/1

Published by the American Institute of Physics 


\title{
Enhanced Model of Photovoltaic Cell/Panel/Array Considering the Direct and Reverse Modes
}

\author{
Abdallah Zegaoui 1,2,3,a), Mohamed Boutoubat ${ }^{4}$, Jean-Paul Sawicki ${ }^{2,3}$ \\ Fatma Zohra Kessaissia ${ }^{1}$, Abdelkader Djahbar ${ }^{1}$, and Michel Aillerie ${ }^{2,3, b)}$ \\ ${ }^{1}$ LGEER Laboratory, Hassiba Benbouali University, BP151, 02000 Chlef, Algeria. \\ ${ }^{2}$ LMOPS, Université de Lorraine, EA-4423, 2 rue E. Belin, 57070 Metz, France \\ ${ }^{3}$ LMOPS, CentraleSupelec, 2 rue E. Belin, 57070 Metz, France \\ ${ }^{4}$ LACOSERE Laboratory, Laghouat University, Algeria. \\ a)Corresponding author: abd.zegaoui@gmail.com \\ b)aillerie@metz.supelec.fr
}

\begin{abstract}
This paper presents an improved generalized physical model for photovoltaic, PV cells, panels and arrays taking into account the behavior of these devices when considering their biasing existing in direct and reverse modes. Existing PV physical models generally are very efficient for simulating influence of irradiation changes on the short circuit current but they could not visualize the influences of temperature changes. The Enhanced Direct and Reverse Mode model, named EDRM model, enlightens the influence on the short-circuit current of both temperature and irradiation in the reverse mode of the considered PV devices. Due to its easy implementation, the proposed model can be a useful power tool for the development of new photovoltaic systems taking into account and in a more exhaustive manner, environmental conditions. The developed model was tested on a marketed PV panel and it gives a satisfactory results compared with parameters given in the manufacturer datasheet.
\end{abstract}

Keywords. Photovoltaic cells, Photovoltaic panels, PV cell/panel modeling, Direct and reverse operating mode, I-V characteristics, Environmental parameters.

\section{INTRODUCTION AND INITIAL BACKGROUND}

The efficiency of photovoltaic (PV) panels and arrays primary depends on the efficiency of the basic elements being the PV cells. A PV cell can operate in the first quadrant of the I-V characteristics as generator or in the second one as receiver. When on PV cell in a string work in this last operating mode, it imposes a reverse voltage against the others PV cells of the string. As shown in Ref. [1-6] and by Zaraket et al. in Ref. [7-10] who have experimentally studying the influence of electrical and thermal stresses on cell efficiency, shadow induces the PV cell to act as load and to consume the power delivered from other un-shading cells, thus inducing a rising of its temperature reaching creation of hot spot. Therefore, the authors in [11] have originally proposed a direct and reverse mode model (named DRM model) able to describe I-V characteristics in both direct and reverse operating mode according to the experiments made on the reverse mode biasing of 60 polycrystalline silicon cells.

The existing models, except the DRM model but even the relatively recent ones based on transistor instead of diode $[12,13]$, do not take into account the reverse operating mode. DRM model accurately reproduce the I-V behavior of PV cells, PV panel and PV array according to the irradiation and the temperature changes. Nevertheless, the influence of the temperature variation is not visible on the I-V characteristics and the influence of temperature changes on the short current in the second operating quadrant was not considered avoiding the consideration of the environmental parameters of the cell in operation.

In the current work and contribution, we present an enhanced DRM model, (EDRM model) for PV cells/panel/array modelling named EDRM considering the influence of temperature variations. The enhanced model hugely improve the existing one as it can be apply to cells or panel or array, not characterized in static mode in laboratory but characterized in real operation modes.

The development done for the EDRM model was supported by experimental I-V characterizations of 60 polycrystalline PV cells in reverse mode produced from the same initial ingot. The I-V characteristics were shown in Fig.1. 


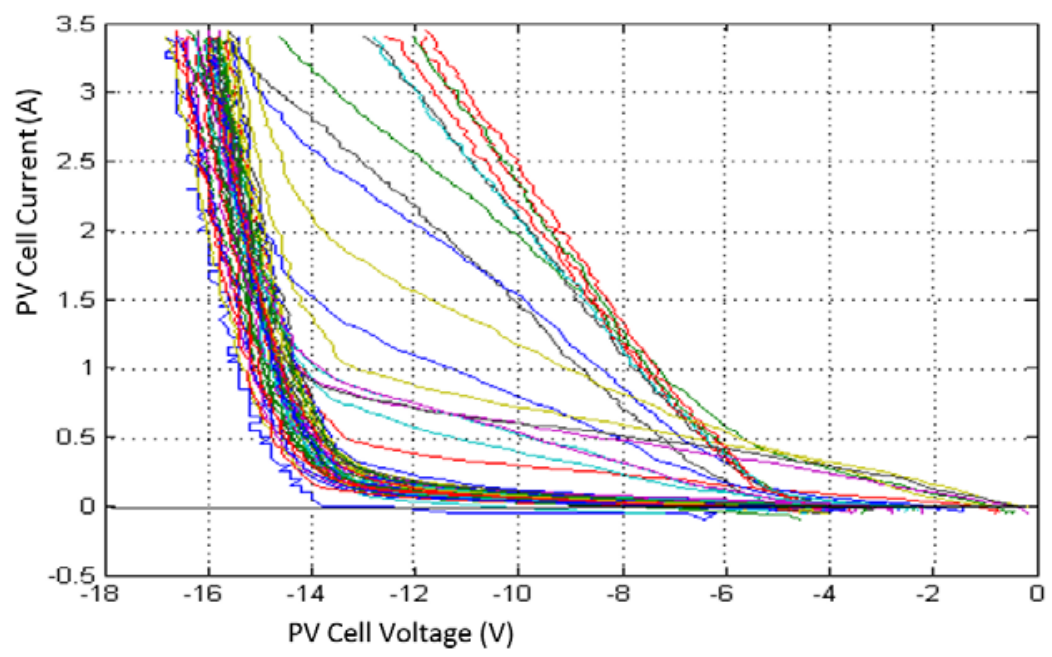

FIGURE 1. Experimental I-V curves of 60 polycrystalline PV cells in the reverse mode biasing. Characteristics extracted from Ref. [11]

From figure 1, we note the presence of a huge discrepancy in the I-V behavior between all PV cells even if the 60 cells provide from the same ingot. We note also the appearance of two avalanche voltages on the reverse mode: the first value is around $-5 \mathrm{~V}$ and the second value close to $-14 \mathrm{~V}$. These experimental finding had brought to propose in Ref. [11] the initial basic DRM model as reported hereafter in Fig. 2 to obtain a self-consistent publication. This model was developed under Orcad/Pspice as shown in Fig.3.

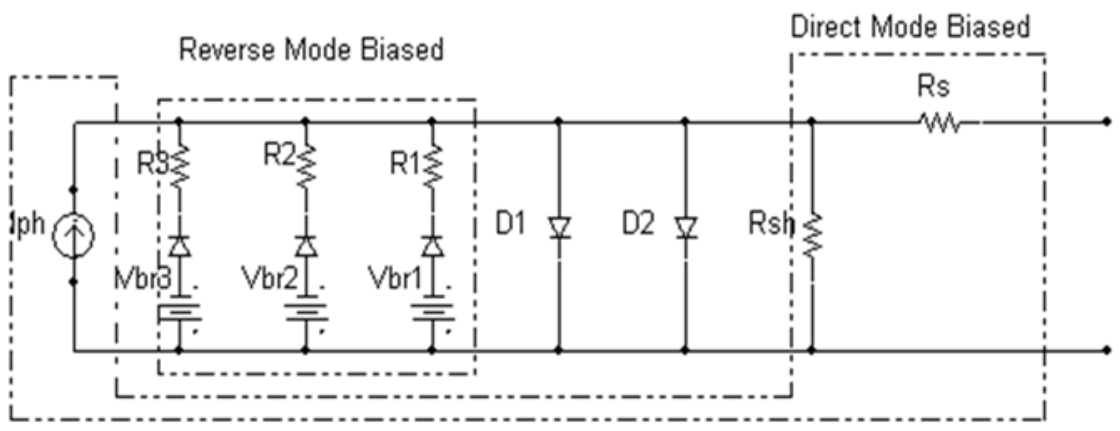

FIGURE 2. The basic DRM model originally developed in Ref. [11].

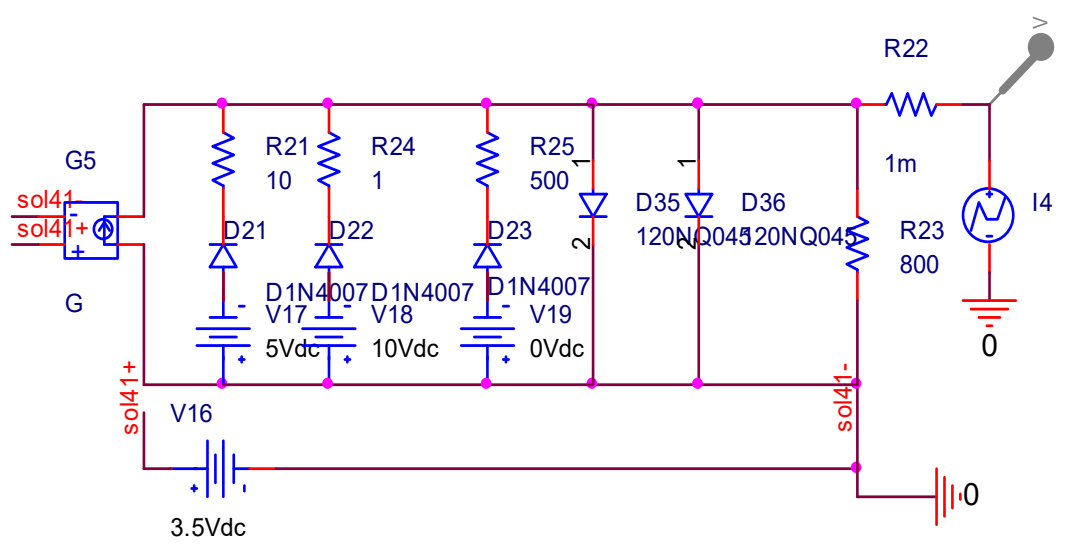

FIGURE 3. The basic DRM model implemented under Orcad/Pspice (from Ref. [11]).

\section{THE NEW ENHANCED DRM MODEL}

Figure 4 show the electronic diagram of the new enhanced DRM model of PV cells. This model improve the basic DRM model as it takes into consideration in the reverse operating mode both the variation of the 
photocurrent and the short circuit current due to environmental parameters' changes, especially link to the influence of temperature variations. The main modification of the basic DRM model is the adding of a diode (D384) able to perfectly reproduce the influence of temperature variations on the photocurrent on the I-V characteristics and on the short current.

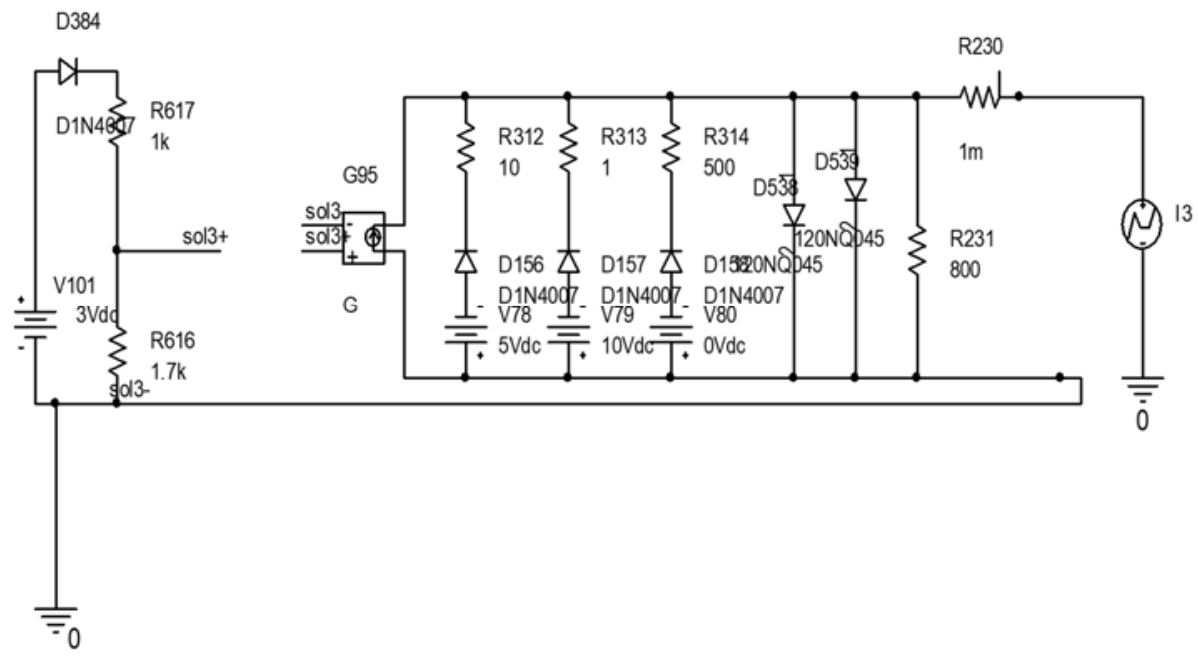

FIGURE 4. The EDRM model for PV cell implemented under Orcad/Pspice.

To test the effectiveness of our approach when temperature changes are considered in the behavior of PV elements, the EDRM model was applied to a PV cell, with the following steps of temperature: $-10,0,25,50,70$, 85 and $100{ }^{\circ} \mathrm{C}$. Fig. 5 shows the I-V characteristics of this PV cell as function of temperature.

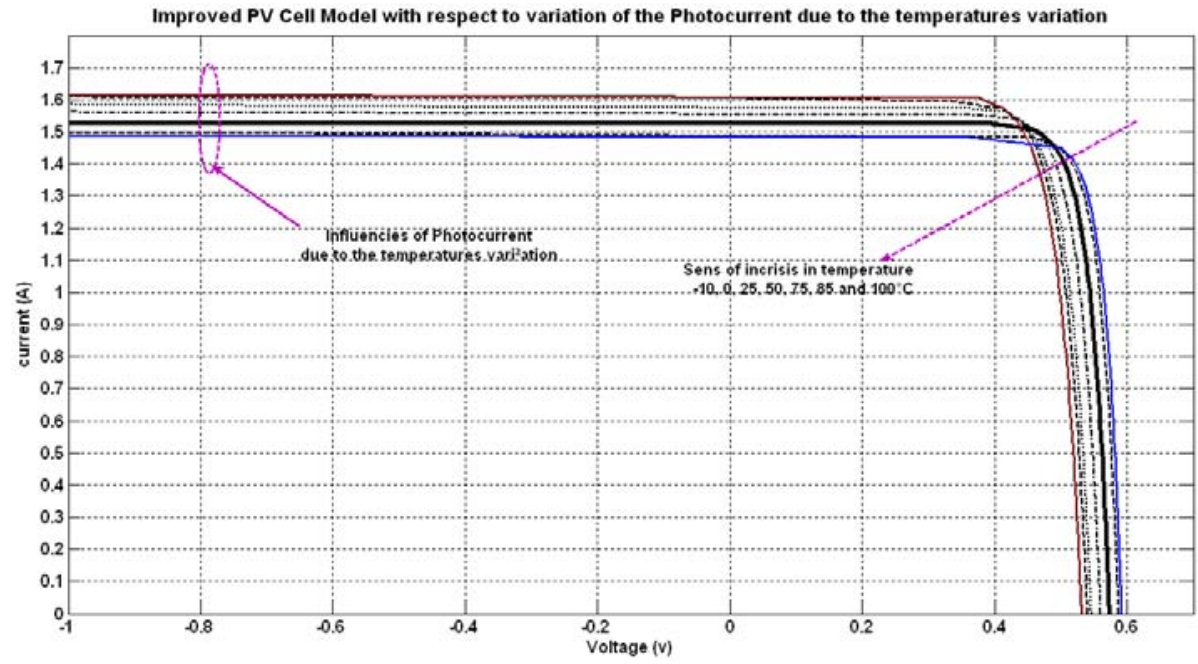

FIGURE 5. I-V characteristics of a PV cell in both direct and reverse mode biasing under influence of temperature changes by applying the EDRM model.

In Fig. 5, one can remark that the rise in temperature causes a decrease of the open circuit voltage inducing a decrease of the maximum power of the PV, as expected by the usual behavior of PV cell with temperature. The the rise in temperature is also at the origin of an increase of the short-circuit current, which directly correspond to an increase of the photocurrent with the temperature. For the specific simulated PV cell, in the temperature range, the short-circuit current rises from 1.5 to up than $1.6 \mathrm{amps}$ for the entire region that the PV cell behaves as a generator, i.e. when it remains in the first quadrant on the I-V characteristics. In the reverse mode biasing, the current keeps the short current values depending to the temperature changes. Nevertheless, the reverse voltage imposed by the PV cell in this second quadrant keeps going up. 


\section{THE EDRM MODEL OF A SHADED MARKETED PV PANEL}

In order to show the influence of both shadow and temperature changes, we have shaded the entire effective surface of one PV cell in the PV panel and then varied the temperature steps by steps as simulated in Fig.5. The corresponding EDRM model of the simulated PV panel was implemented under Orcad/Pspice software. It corresponds to an extension of the EDRM model shown in Fig. 4 for one cell. Indeed, for the modeling of a panel, the model is simply built with an association in series and in parallel of the EDRM model for one cell according to the datasheet of the solar module configuration under test.

The BP solar module BP350J is a 50Wc PV panel composed by two parallel strings of 19 polycrystalline silicon PV cells. Its open voltage value and short current value are $21.8 \mathrm{~V}$ and $3 \mathrm{~A}$ under STD operating conditions, respectively. The maximum power point coordinates in the $\mathrm{I}-\mathrm{V}$ characteristics plane are $(2.9 \mathrm{~A}, 17.5 \mathrm{~V})$. Only one by-pass diode is mounted for its protection against inverse current that could be induced by hot spots due to shading on the surface of the panel. The I-V characteristics, under temperature variations, as provided by manufacturer in the datasheet, are shown in Fig. 6.

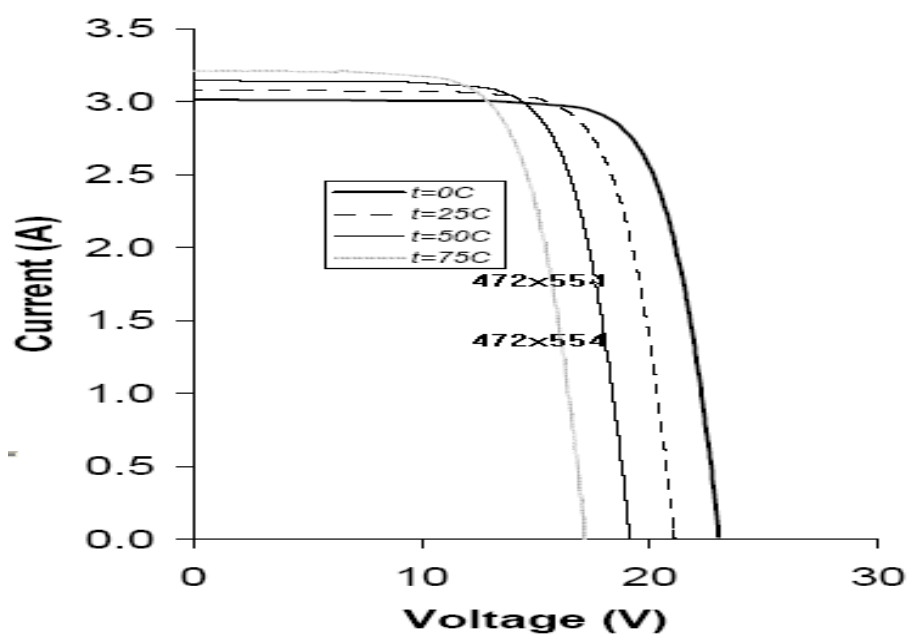

FIGURE 6. Influence of temperature variations on the I-V characteristics of PV BP solar BP350J from manufacturer datasheet.

Simulated results of I-V and P-V characteristic curves due to the temperature variations were presented in Figs. 7 and 8, respectively. Mainly in Fig. 7, we present the influence of the temperature variations on the I-V characteristics of the simulated shadowed BP350J PV BP solar with a zoom around the short circuit current area; whereas in Fig. 8, we present the displacement of the local MPP on the P-V characteristics of the BP350J solar panel under partial shadow and temperature changes.

Some pertinent information can be extracted of these figures. At first, as it is well-known, and independently of the temperature values, these figures enlighten the direct effect of the shadow on the global energetic performance of the panel. Indeed, the electrical characteristics present knees for the I-V ones and power local maximums on the P-V ones. It is to be noted that the presence of local maximum power points is at the origin of large problem in the operation of converters or inverters whose one main function is to track the maximum power point so as to convert the maximum power. At second, these figures confirm, as it is also well-known, that the temperature rise induce a global decrease of the delivered power. Finally, the efficiency of the EDRM model and it pertinence in the modeling of shading effect are confirmed by the change with temperature of the short circuit current and on the open voltage circuit, observed in Figs. 7 and 8 with a faithful reproduction of values given by the manufacturer and shown in Fig. 6. 

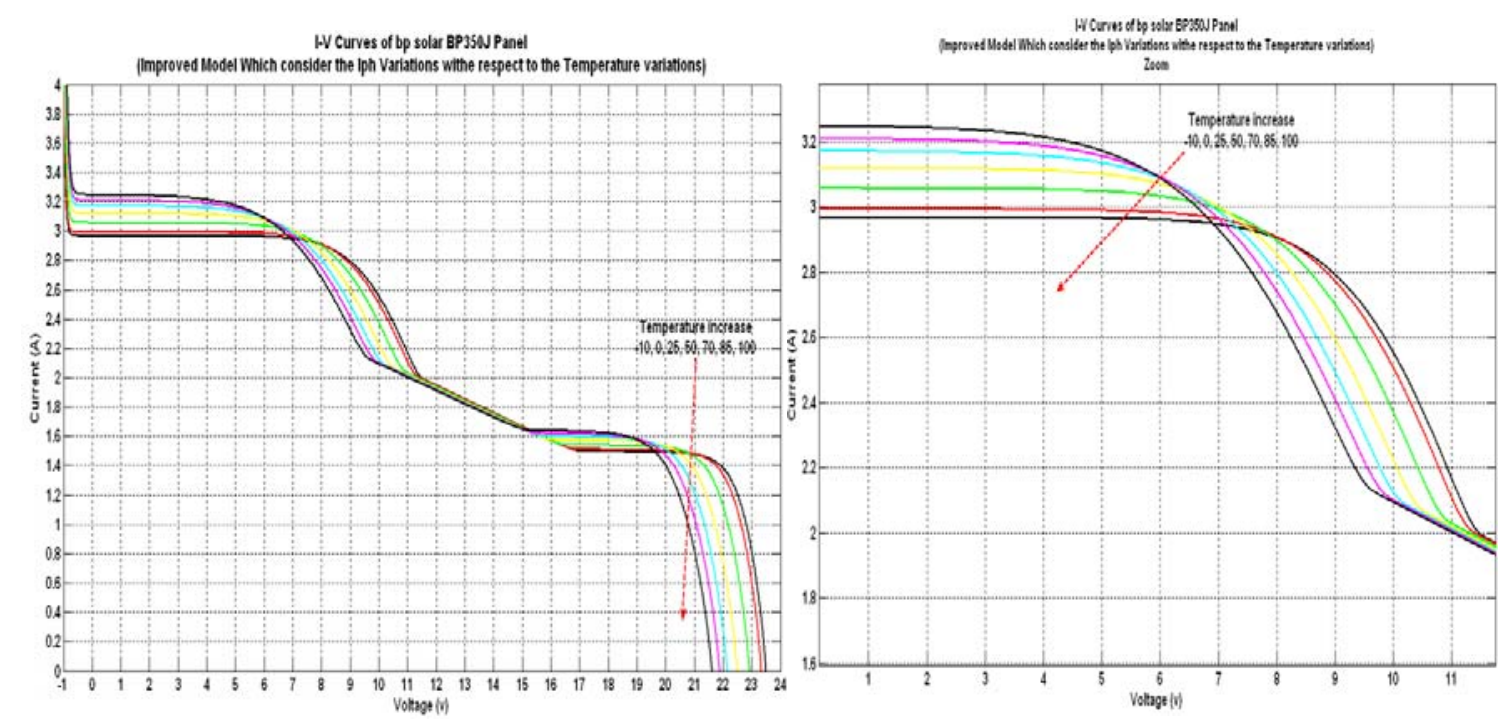

Figure 7. Influence of the temperature variations on the I-V characteristics of the simulated shadowed BP350J PV BP solar with a zoom around the short circuit current area.

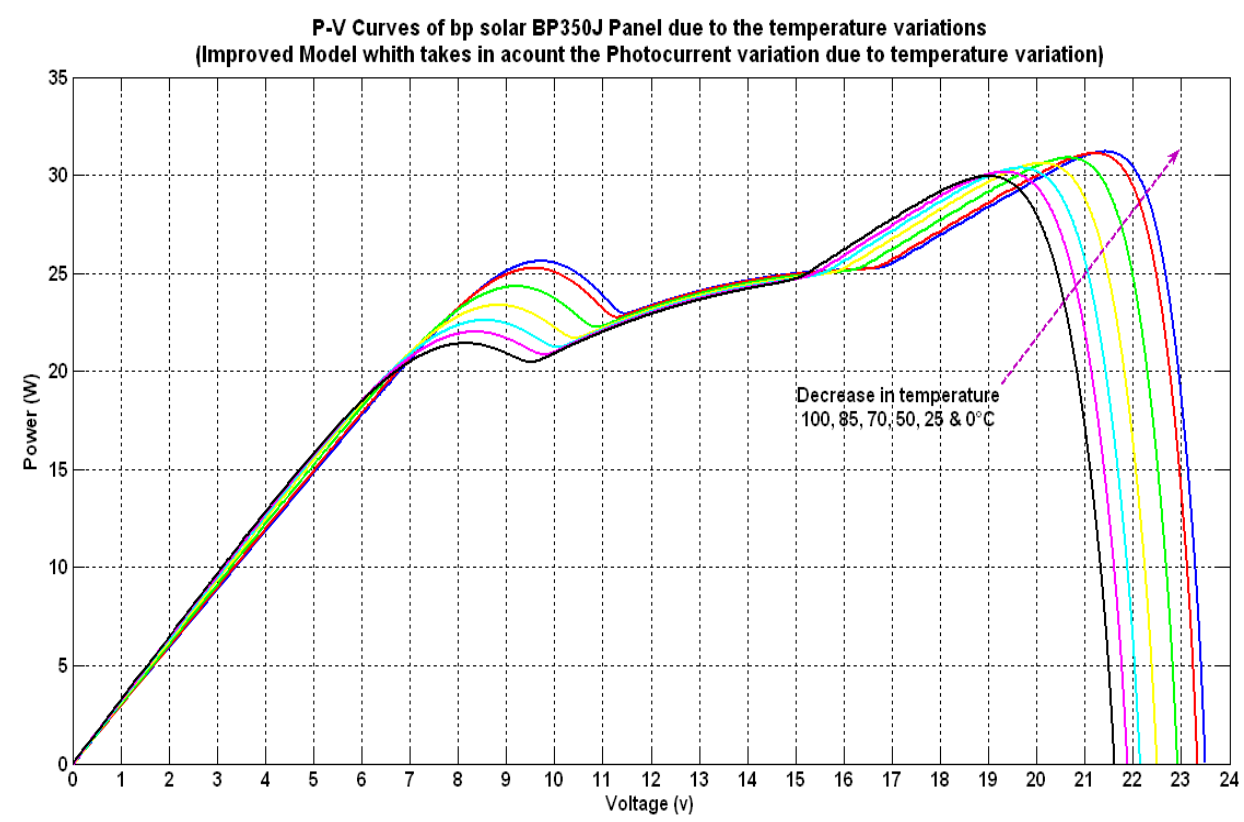

FIGURE 8. Displacement of the local MPP on the P-V characteristics of the BP350J solar panel under partial shadow and temperature changes.

The temperature influence on the current is evaluated thanks to the EDRM model by a value equal to 0.06445 $\mathrm{mA} /{ }^{\circ} \mathrm{C}$. So, the short circuit current is affected by a rate value equal to $0.064 \% /{ }^{\circ} \mathrm{C}$. This value is nearby the value mentioned by the manufacturer in the panel datasheet, which is $0.065 \% /{ }^{\circ} \mathrm{C}$. This result proves the faithfulness of the new proposed EDRM model for modeling PV cells, but also, as shown here, PV panels obtained by duplicating the model for one cell and one can easily imagine that the EDRM model will be also faithful for the modeling of PV arrays extending the EDRM model presented above for a panel, with now, the respect of the specific seriesparallel configuration of the wide array.

\section{CONCLUSION}

In this work, a new general enhanced physical model for PV cells, panels and arrays operating in both direct and reverse biasing modes is proposed. The new model, named EDRM, is based on the use of a conventional one or two diode models used for modeling of PV cell. Experiments were performed on polycrystalline PV cells 
operate in the reverse biased mode and experimental results are compared to the simulated ones. The EDRM model is able to reproduce the influence of environmental variables, i.e. temperature and irradiation on the I-V and P-V characteristics in both the first and the second quadrant of the operating modes. The are affected by temperature variations, our simulations are validated by the fact that the changes of the photocurrent and as a result the short circuit current are in the same direction as the temperature variations. To prove the validity of the proposed model, the degree of the temperature influence on the photocurrent is compared to that mentioned on the I-V curves of a marketed PV panel. We have shown that the EDRM model faithfully reproduce the characteristics expected in the case of shading with the values of the short-circuit current and the open circuit voltage given by the manufacturer. An extension in applicative possibilities of the EDRM model is the modeling of PV arrays, which is easily possible using a series-parallel combination of the EDRM model of a panel.

\section{REFERENCES}

1. K. Naka, N. Yonekura, S. Yamanaka, H. Kawamura, H. Ohno, K. Naito, H. Kawamura, "Simulation of i-v characteristics of a pv module with shaded pv cells", Elsevier, Solar Energy Materials \& Solar Cells 75, 613-621 (2003).

2. C.-S. Tu, Y.-J. S. , H.-L. Tsai, "Development of generalized photovoltaic model using matlab/Simulink", Proceedings of the world congress on Engineering and Computer Science WCECS2008- ISBN: 978-98898671-0-2 (2008).

3. J. Bishop, "Computer simulation of the effects of electrical mismatches in photovoltaic cell interconnection circuit", Elsevier, Solar Cell 25, 73-89 (1988).

4. R. Campbell, "A circuit-based photovoltaic array model for power studies", IEEE Trans. North American Power Symposium-NAPS 2007, 98-101 (2007).

5. J. Gow, "Development of photovoltaic array model for use in power-electronics simulation studies", IEE Proc.-Electr. Power Appl. 146, 2, 193-200 (1999).

6. A. Zegaoui, P. Petit, J. Sawicki, J. Charles, M. Aillerie, "Simulation of photovoltaic generators and comparison of two common maximum power point trackers", International Conference on Renewable and Power Quality (ICREPQ'10).

7. J. Zaraket, T. Khalil, M. Aillerie, G.A. Vokas, C. Salame, “The Effect of Electrical stress under temperature in the characteristics of PV Solar Modules”, Energy Procedia, 119, 579-601 (2017).

8. J. Zaraket, M. Aillerie, C. Salame, "Dark and illuminated characteristics of photovoltaic solar modules. Part I: Influence of dark electrical stress", AIP Conference Proceedings 1758(1) 020016 (2016).

9. J. Zaraket, C. Salame, M. Aillerie. "Dark and illuminated characteristics of photovoltaic solar modules. Part II: Influence of light electrical stress", AIP Conference Proceedings 1758(1), 030052 (2016).

10. J. Zaraket, T. Salame, C. Salame, M. Aillerie "Parameters and characteristics of PV solar modules under the influence of thermal stresses", AIP Conference Proceedings 1814, 020055 (2017).

11. A. Zegaoui, P. Petit, M. Aillerie, J.P. Sawicki, A.W. Belarbi, M.D. Krachai, and J.P. Charles, "Photovoltaic Cell/Panel/Array Characterizations and Modelling Considering both Reverse and Direct Modes", Energy Procedia 6, 695-703 (2011).

12. A. Zegaoui, M. Aillerie, P. Petit, and J.P. Charles. Universal Transistor-based hardware SIMulator for real time simulation of photovoltaic generators. Solar Energy 134, 193-201 (2016).

13. P. Petit, A. Zegaoui, M. Aillerie, J.P. Sawicki, and J.P. Charles, "The Transistor based Direct and Reverse Mode model for photovoltaic strings and panels", Energy Procedia 18, 1240-1246 ( 2012 ). 